\section{Causes of magmatic diversity}

\section{Bruce Marsh}

What Charles Darwin did for organisms he also did for volcanic rocks: he explained diversity using a simple evolutionary principle and gave magmatists a source of endless controversy. Black basalts, separated by some 25 weight per cent in $\mathrm{SiO}_{2}$ content from pink granites, can progressively change, by continual separation of early forming crystals, into a much more refined granitic composition. This is fractional crystallization, the technique used by Curie to purify uranium ores. It is easily invoked in magmas because, without exception, magmatic crystals differ markedly in composition from their multicomponent parent melt. Solid-liquid density contrasts encourage relative motion and separation of phases to yield a liquid line of descent linking basalts to granites. This classical model has suffered greatly over the past twenty years, mostly from the findings of the new field of magma-physics studies, which suggest that magmas are highly turbulent and not conducive to crystal settling. The findings of Cox and Mitchell, reported on page 447 of this issue ${ }^{1}$, indicate that the tide is turning back towards classical explanations. They show that sequential eruptions of crystal-laden and crystalfree basalts from the Deccan plateau in India are compositionally connected through their crystal content and density contrast.

Magmatic diversity has always been recognized as a complex problem. Huge Hawaiian magmatic systems, highly fluid and laced with sinkable crystals, produce only basalt. Tiny, sluggish island arc volcanic centres, barely able to sustain more than a few successive eruptions, show good diversity. Why? Part of the answer, until recently, seemed to be related to the convective dynamics of the magma itself. Large vats or magma chambers beneath volcanoes convect as they cool, crystallize and fractionate. The vigour of convection in these often sheetlike bodies depends on the rate of heat transfer, magma viscosity and the size of the system. Large, highly fluid, nearsurface chambers would convect turbulently prohibiting crystal settling, whereas small, viscous, crystal-rich chambers would be largely stagnant, allowing efficient crystal fractionation.

Thickly ponded Hawaiian magma, large enough to constitute respectable magma chambers, drilled during 30 years of cooling, gives clear evidence that these bodies are not turbulently convecting, and may in fact be closer to stagnancy (see figure). These lava lakes cool as if domina- ted by conduction ${ }^{2}$, and small dribbles of fractionated liquid from the floor traverse the chamber without destruction by mixing ${ }^{3}$. The body crystallizes at the chamber roof and floor, by forming crusts that trap nearly all the remaining fractionated fluid. This cool, dense fluid would normally drive the magma convection were its viscosity insensitive to temperature. The hot inner parts of the body are

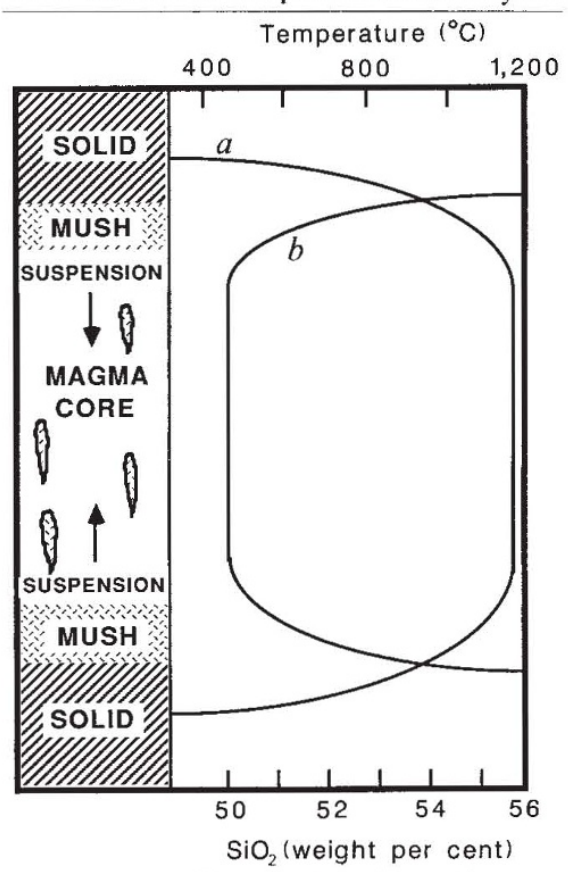

Schematic of an Hawaiian lava lake, 100 metres deep, some 10 years after emplacement ${ }^{3}$. Crusts grow inwards from the top and bottom margins. A low crystallinity suspension zone and a higher crystallinity mush zone form the inner reaches of each crust. The innermost temperature $(a)$ is still that of the initial body. The silica content $(b)$ of the interstitial liquid, a measure of degree of fractionation, rises sharply within the suspension, mush and crust regions, but only inwards of the suspension zone is such liquid eruptable. Small driblets of this refined melt leak up from the lower crust and reach the upper without convective mixing.

protected from the cooler country rock by these insulating blankets or crusts. Although rising gas bubbles and the downward growing crust can capture suspended crystals, most crystals initially in the rising magma settle out, despite convection.

New crystals grow near and within the propagating crusts, and are excluded from the hot inner core of the body where they remelt ${ }^{4}$. But these bodies do not produce large volumes of fractionated magma because the most fractionated liquids are trapped in the crusts, apart from the occasional small driblet that escapes from the floor. The crusts growing on vertical side walls similarly capture viscous, refined melt as it flows sluggishly up through the porous crust to collect at the roof. So it is not convection, but crust, that inhibits fractionation.

Cox and Mitchell have looked at basalts in the Deccan plateau in Northern India which was magmatically active 65 million years ago. Thus rather than looking at existing magma chambers, they have to infer the magma dynamics from evolved basalts. By assuming that successive lavas are accurate samples or snapshots of the evolution of an associated magma chamber, they find that the initial crystal content of the magma was so high that once the crystals had settled out, the magma produced a highly fractionated liquid. Further fractionation of these crystal-free liquids would have been impossible because all later crystals grow near crust which traps them and prohibits crystal settling.

The nature of the convective state is intimately tied to the dynamics of solidification $^{5}$. Convection in magma chambers does not depend on the full thickness of the system, as it does in layered systems heated from below ${ }^{6}$ which leads to turbulence, but depends on the ratio of the thermal diffusivity to the solidification rate. Rapid, early growth of crust inhibits convection, which sets in later, is gentle and hugs the upper crust, not reaching the floor at all. Cooling at the base further encourages stagnancy near the floor?; there is no basal inward heat flux to stimulate convection ${ }^{8}$. The initial inner crystals are free to settle or remain in suspension. Even if the body is suddenly heated from below by influx of new, denser magma and convection becomes vigorous, crystal settling continues".

While models of fractionation have varied between extremes, most workers have ploughed along using the timehonoured edict 'when in doubt, settle it out'. As it turns out, this is only partly true in the sense that it is necessary to know how and where to 'settle it out'. The appreciation of the subtle balance between cooling, solidification, convection, phase equilibria, rheology and crystal sorting greatly increases our understanding of magma dynamics and magmatic diversity.

\footnotetext{
1. Cox, K.G. \& Mitchell, C. Nature 333, 447-449 (1988).

2. Peck. D.L., Hamilton, M.S. \& Shaw, H.R. Am. J. Sci. 277 415-437 (1977).

3elz. R.A. Geochem. Soc. spec. publ. No. 1. 241-258 (1987)

4. Mangan. M.T. \& Marsh. B.D. Am. geophys. Un. Trans. 69 526 (1988).

5mith, M.K. J. Fluid Mech. 188, 547-570 (1988).

6. Huppert. H.E. \& Sparks, R.S.J. Contr. Min. Petrol. 75 279-289 (1980).

Jaupart, C., Brandeis, G. \& Allegre, C.J. Nature 308, 535 538 (1984).

8. Carrigan. C.R. Geophys. Res. Lett. 14, 915-918 (1987). 9. Martin, D. \& Nokes, R. Nature 332.534-536 (1988)
}

Bruce Marsh is in the Department of Earth and Planetary Sciences, Johns Hopkins University, Baltimore, Maryland 21218, USA. 